\title{
Research on the Combination of P2P Network Credit and Insurance Based on Game Theory
}

\author{
Pengcheng $\operatorname{Han}^{1,}$, Xubin $\mathrm{Li}^{1, \mathrm{~b}}$ and Chaoyi Guo ${ }^{1, \mathrm{c}}$ \\ ${ }^{1}$ Economic and Management Department, Tianjin University of Science \& Technology, Tianjin \\ 300222, China \\ a416325745@qq.com, b2401821674@qq.com, cguocy@mail.tust.cn
}

\begin{abstract}
Keywords: game theory, P2P network credit, insurance
Abstract. Since the P2P network credit appeared in China in 2007, it has experienced nearly 8 years of development. But we should notice the following debt defaults, which caused a lot of social problems, becoming even more regular along with its expansion. The occurrence of these violations shows great risk behind the traditional P2P network credit, so how to keep the risk within reasonable limits will be vital for the following P2P network credit study. This paper tries to start from the perspective of game theory, combined the network credit with insurance industry to find a reasonable way for the risk control of P2P network credit.
\end{abstract}

\section{Introduction}

Peer to peer (P2P) network credit comes from P2P microfinance which breakthrough the limitation of microfinance, it has stronger ability of risk spreading. At the same time it can solve the problem of shortages of traditional microfinance funding and become an emerging mode of financial management for small investors now.

P2P network credit is a kind of innovative financing which get the Internet technology, electronic commerce technology, financial service mode and folk lending together. In this mode, according to the network platform, the borrower and the lender can exchange on both sides of the personal information, resources, capital and other necessary information instead of financial institutions. P2P mode has become sunrise industry in the financial industry which been favored by more and more people because of its low threshold, lending facilities, and relatively fair lending conditions [1].

P2P network credit, however, faces many risks: borrower credit risk, registered users information security risk, platform, operational risk, and so on. Because our country has not set up perfect personal credit system, the borrower credit risk has become the biggest risk to the P2P network credit. The future development of P2P network credit is directly affected by whether we can effectively identify the borrowers and control their credit risk. How to control the risk in a reasonable scope will be one of the important directions of P2P within a long period of time in the future. This paper tries to start from the perspective of game theory, combined the network credit with insurance industry to find a reasonable way for the risk control of P2P network credit.

\section{Overview of the P2P Network Credit}

Related Meaning. P2P network credit originates from P2P microfinance. Initially, the Grameen Bank of Bangladesh founded by Professor Yunus provided unsecured microfinance for more than 2 million rural poor population of the country (especially women) by using the P2P mode. The bad debt rate of this mode is far below the level of interbank, and greatly promoted the progress in rural Bangladesh [2].

P2P network credit is a financial model that individuals with funds and willingness to provide small loans to other people who are in need of funds by the way of credit loan (or the certain guarantee) through the P2P network credit platform and other intermediary agencies. Most platforms will examine the situation of borrower and charge to the borrower and lender respectively. Due to the breakthrough of microfinance limitations, the P2P network credit has stronger ability in risk 
diversification, also can solve the problem of shortage of funds for microfinance. It has become a new way of financial management for small investors.

The Function in the Operation of Financial System in China. Up to now, P2P network credit mainly active the financial market in the first-and second-line cities of China, so that the private idle funds have been better used, furthermore, the difficulties of individuals, small and medium-sized enterprises capital turnover have been relieved to a certain degree. From the macro level, P2P network credit is very important to the operation of China's financial system:

It is based on the service of low-income class which has the public welfare property. The main service group of $\mathrm{P} 2 \mathrm{P}$ credit is low and medium income earners for which more and more $\mathrm{P} 2 \mathrm{P}$ platform opened a separate plate in the public welfare of small loans. Generally, public welfare sector is committed to encourage students to start a business, to help small owners and so on.

It makes up for the blank of the financial market and meets the needs of small amount of financial demand. Currently, financing needs of ordinary people, small and medium-sized enterprises can't be met effectively. The situation of narrow channels and high cost restricted the development of domestic micro economy, while $\mathrm{P} 2 \mathrm{P}$ model replaced the traditional investment and financing channels and then brought a simple and efficient financing opportunity for individuals and small and medium business owners.

It is the practice of financial network. P2P network credit uses the Internet directly for loan transaction which is the core of the financial industry. On this basis, there will be more financial business model appeared on the Internet.

It will be able to establish the integrity of the whole society. Unsecured credit loan adopted by P2P network credit is based on atmosphere of the whole society. In order to guarantee the repayment, the platform will establish a set of independent credit evaluation system by the way of data sharing in commercial banks, which makes the credit translate into the wealth. Therefore, the requirement of a borrower with a high credit rating will be given priority to meet at a lower interest rate, and everyone will cherish their own credit virtually.

The platform will accumulate big data. Based on the accumulated data, we can sum up the financial demand of individuals and small and medium-sized enterprises in our country from the scale of funds, geographical, repayment methods, loan time, interest rates and other dimensions. Furthermore, we can also dig out the risk bearing capacity, operational efficiency, the industry's investment returns and so on. According to the effective data above, the personalized marketing can be prompted by financial institutions. In addition, the data collected by the data platform of P2P network credit can also be directly applied to the personal credit system of central bank.

It can reasonably guide the private investment and financing. Compared to the traditional one-on-one loan, P2P network credit reallocates the funds of lenders and lends them to different debtors. Both lenders and borrowers compete in the capital market through competitive bidding, which will form an effective range of interest rates. This volatility which is more attractive than the bank deposit rate of return, can reasonably guide the private investment and financing $[3,4]$.

\section{Overview of Game Theory}

Fundamentally, game theory is to research the optimal decision problems under the conditions of the real world confrontations using rigorous mathematical model. It is a science of making a decision when the behavior of decision-making body has a direct interaction with mathematical methods, and of studying the equilibrium problem of the decision-making

Game theory believes that as the individual utility function depends not only on the individual's own choice, but also affected by other individual's choice, the best choice is a function of other people's choice. In this sense, game theory is studying the personal choice problem on the condition of mutual external economic conditions [5].

Equilibrium is one of the most important ideas in game theory. When the game reaches equilibrium, each player in the board cannot increase interest by unilaterally changing their strategy, so in order to maximize their own interests, the game parties choose a certain optimal strategy and 
reach some kind of temporary equilibrium with other rivals. This balance can be maintained long term, if the parties adhere to the original principle of maximizing the interests and face reality rationally in the case of the external environment does not change. Game purpose is to analyze the game equilibrium strategy of the parties.

\section{Feasibility Analysis of Introducing Insurance}

As everything has two sides, we should notice all kinds of risks behind the P2P network credit while focusing on its boom. Various financial default events make us pay attention to the credit risk which has become the greatest potential risk of P2P network credit industry. It's subjected to certain constraints since the credit system is not sound, national financial risk awareness is weak, the frequent occurrence of non standard behavior in the market and policy uncertainty.

Therefore, when planning the P2P development strategy, we should make more rigorous analysis and control of the risk factors. Only by identifying the induced factor of risk correctly and mastering the characteristics and trend of credit risk can we prevent and relieve it [6].

It is generally known that the insurance industry is a traditional offline risk control industry. Through combination of the insurance industry and the emerging P2P network credit, on the one hand we can control the network credit risk, on the other hand it makes insurance from offline to online, so it can win the new win the new development space, achieve advantages complement as well as cooperation and win-win situation. This paper tries to analyze the game from the two angles of the fund-raisers and investors by constructing basic game model so that we could combine insurance, as an effective tool to control risk, with $\mathrm{P} 2 \mathrm{P}$ network credit of which the risk could be controlled from the root.

\section{Analysis under the Game Theory Model}

First of all, assuming that the fund-raiser should pay a certain fee $\mathrm{C}$ before he borrow money on the P2P Internet platform, and pay another fee $\mathrm{P}$ to the insurance company after the insurance participation. After raising funds $\mathrm{F}$, the fund-raiser starts operation, in the case of the expiration of the term of operation and success, the fund-raiser can get the expected benefits $q \mathrm{~F}, q$ represents the probability that the business will succeed, its value between 0 to 1 . Expected return is $q \mathrm{~F}-\mathrm{C}$ in the absence of insurance, and it changes into $q \mathrm{~F}-\mathrm{C}$ - $\mathrm{P}$ in the case of insurance. Fund-raiser without insurance may get operating loss in the case of improper operation, the expected loss is $(1-q) \mathrm{F}+\mathrm{C}$. At this time, the insurance fund-raiser will get a sum of insurance claims $i \mathrm{P}(i>1)$. From the investor's perspective, in order to get a profit $\mathrm{R}$, it needs to put in a certain cost in the early stage which is the funds $\mathrm{F}$ raised by fund-raiser. Investor can get the expected return $q(\mathrm{~F}+\mathrm{R})$ in the case of the normal operation of the fund-raiser regardless of the insurance. Conversely, the investor with insurance will receive $i \mathrm{P}(i>1)$ more in insurance coverage than the fund-raiser without insurance.

Table 1. Game model of insurance

\begin{tabular}{|c|c|c|c|}
\hline Participants & Category & No Insurance & Insurance \\
\hline \multirow{3}{*}{ Fund-raiser } & Financing Cost & $\mathrm{P}$ & $\mathrm{C}+\mathrm{P}$ \\
\cline { 2 - 4 } & Expected Return & $q \mathrm{~F}-\mathrm{C}$ & $q \mathrm{~F}-\mathrm{C}-\mathrm{P}$ \\
\cline { 2 - 4 } & Expected Loss & $(1-q) \mathrm{F}+\mathrm{C}$ & $(1-q) \mathrm{F}+\mathrm{C}-i \mathrm{P}$ \\
\hline \multirow{3}{*}{ Investor } & Investment Cost & $\mathrm{F}$ & $\mathrm{F}$ \\
\cline { 2 - 4 } & Expected Return & $q(\mathrm{~F}+\mathrm{R})$ & $q(\mathrm{~F}+\mathrm{R})$ \\
\cline { 2 - 4 } & Expected Loss & $(1-q) \mathrm{F}$ & $(1-q) \mathrm{F}-i \mathrm{P}$ \\
\hline
\end{tabular}


We use the simplest formula for the expected return and the expected loss to calculate and draw: The expected return of the fund-raiser without insurance is:

$q \mathrm{~F}-\mathrm{C}-[(1-q) \mathrm{F}+\mathrm{C}]=2 q \mathrm{~F}-2 \mathrm{C}-\mathrm{F}$

The expected return of the fund-raiser with insurance is:

$q \mathrm{~F}-\mathrm{C}-\mathrm{P}-[(1-q) \mathrm{F}+\mathrm{C}-i \mathrm{P}]=2 q \mathrm{~F}-2 \mathrm{C}-\mathrm{P}-\mathrm{F}+i \mathrm{P}$

As is known to all, if an event of default occurs, the amount of insurance payment must be greater than the premium (i.e. $i>1$ ), so (2) - (1) $=i \mathrm{P}-\mathrm{P}>0$. This shows that the expected return for the fund-raiser with insurance is higher than that without insurance.

Similarly, the expected return of the investor without insurance is:

$q(\mathrm{~F}+\mathrm{R})-(1-q) \mathrm{F}=2 q \mathrm{~F}-q \mathrm{R}-\mathrm{F}$

The expected return of investors with insurance is:

$$
q(\mathrm{~F}+\mathrm{R})-[(1-q) \mathrm{F}-i \mathrm{P}]=2 q \mathrm{~F}-q \mathrm{R}-\mathrm{F}+i \mathrm{P}
$$

If the insurance payment event occurs, the amount is bound to be greater than zero, so (4) - (3) = iP $>0$, therefore, compared with investors without insurance, investors with insurance get a higher expected return.

\section{Conclusions}

From the perspective of fund-raisers and investors, the return of P2P network credit behavior with insurance is higher than that without insurance. Because from the point of view of fund-raiser, although the insurance raised the threshold of the loan and reduced the expected return, but in the case of loss, the insurance payment will relieve the fund-raiser's repayment pressure. As long as the payment of insurance is higher than the premium paid by the fund-raiser, the return of fund-raiser with insurance in P2P credit behavior is higher than that without insurance. From the perspective of investors, they do not need to pay the costs for fund-raiser's premium in P2P credit behavior, so the insurance payment will greatly reduced investors' risk cost when the investment fails. Investors with insurance will be able to get access to the funds quickly and easily, the intervention of insurance can also provide capital security for the possible investment failure and reduce the worries of investors. Therefore, under the assumption of rational people, investors are more willing to invest in fund-raisers with insurance, thus prompt fund-raisers to attract investment more quickly and then complete the subject of investment. This shows that the introduction of insurance in P2P credit behavior is reasonable.

\section{References}

[1] K. Michael: Peer to Peer Lending: Auctioning Microcredits over the Internet. Social Science Electronic Publishing (2008)

[2] J. Ding: Research on P2P Lending Platform and Online Borrowers-The Case of PPDai.com. . Southwestern University of Finance and Economics (2012)

[3] D. Fudenberg, J. Tirole: Game Theory. Mit Press Books Vol.1 No.7 (1991), p. 841-846

[4] M. Klafft: Online Peer-to-Peer Lending: A Lenders' Perspective. Ssrn Electronic Journal Vol.2 No.2 (2008), p. 371-375. 
[5] J. Wu, Y. Xu: A Decision Support System for Borrower's Loan in P2P Lending. Journal of Computers Vol.6 No.6 (2011), p. 1183-1190.

[6] D. Wang: Feasibility analysis of the model of rural credit + insurance. Xinjiang Finance No.1 (2009), p. 39-42. 